\author{
Банщикова Татьяна Николаевна, Ширяева Ирина Сергеевна
}

\title{
КРОСС-КУЛЬТУРНЫЕ ОСОБЕННОСТИ САМОРЕГУЛЯЦИИ И СОВЛАДАЮЩЕГО ПОВЕДЕНИЯ КАК ОСОЗНАННЫЕ ПРОЦЕССЫ ПРЕОДОЛЕНИЯ ТРУДНЫХ ЖИЗНЕННЫХ СИТУАЦИЙ ${ }^{1}$
}

На основе анализа теоретических воззрений на проблему трудных жсизненных ситуаций раскрывается потенциал когнитивных механизмов в совладании с трудныли жизненными ситуациями. Системный анализ и синтез теоретических положений раскрывает роль осознанной саморегуляции, совладающего поведения (копин-стратегий) в ситуации социокультурной адаптации, пережсивания иностранныли обучаюиимися аккультурационного стресса. Представлен обзор современных подходов к исследованию совладания с трудными жсизненными ситуациями, а также положсния о детерминационной роли сочиокультурных факторов в саморегуляци и выборе стратегий совладания.

Ключевые слова: саморегуляция, совладающее поведение, социокультурная адаптация, трудные жсизненные ситуации, копинг-стратегии.

\section{Tatyana Banshchikova, Irina Shiryaeva \\ CROSS-CULTURAL FEATURES OF SELF-REGULATION AND RELATED \\ BEHAVIOR AS A CONSCIOUS PROCESS OF OVERCOMING DIFFICULT LIFE SITUATIONS}

Based on the analysis of theoretical views on the problem of difficult life situations, the potential of cognitive manifestations in difficult life situations is revealed. System analysis and synthesis of theoretical principles reveal the role of conscious self-regulation, sociocultural adaptation, experience by foreign students of acculturation stress. A review of modern approaches to the study of coping with difficult life situations is presented. Provisions on the determining role of sociocultural factors in self-regulation and the choice of coping strategies are presented.

Key words: self-regulation, coping behavior, sociocultural adaptation, difficult life situations, coping strategy.

Bвedeниe / Introduction. Процесс интеграции российской системы высшего образования в общеевропейское образовательное пространство ставит перед современным вузом приоритетные задачи экспорта качественных образовательных услуг. Россия стала привлекательной для иностранцев, и в наши вузы приезжают студенты из разных стран. Вместе с задачами повышения качества образовательных услуг актуализируется проблема оптимальной помощи студентам в адаптации к новым социокультурным условиям.

Социокультурная адаптация - это трудная жизненная ситуация, с которой сталкиваются иностранные студенты, приехавшие для обучения в другую страну. Это сложный, длительный по времени, многоплановый процесс взаимодействия личности и новой социокультурной среды, в ходе которого студенты, имея специфические этнические и психологические особенности, вынуждены преодолевать разного рода барьеры, осваивать новые формы поведения, испытывая физический и психологический стресс.

\footnotetext{
Исследование выполнено при финансовой подлержке РФФИ в рамках научного проекта № 17-06-00804-ОГН ОГН-А «Осознанная саморегуляция и совладающее поведение в условиях адаптации студентов к новой социокультурной среде: общие закономерности и кросс-культурные различия).
} 
Внимание науки к проблеме адаптации иностранных обучающихся акцентировалось на исследованиях межкультурной адаптации (Н. М. Лебедева, Л. Г. Почебут, А. А. Реан, J. W. Berry, Y. М. J. van Osch и др.), аккультурации (А. Б. Вершок, В. В. Гриценко, А. А. Налчаджян, B. Н. Павленко, Т. Г. Стефаненко, В. Ю. Хотинец, D. Birman, W. Y. Chan, R. Brown, L. Celest, C. Matera,), трансформации этнической идентичности в новых социокультурных условиях (Г. У. Солдатова, А. Н. Татарко, M. Blohm, D. Cohen, Н. Du и др.).

Несмотря на многочисленные теоретические и эмпирические исследования данной проблемы, возникает необходимость осмыслить роль саморегуляции и совладающего поведения как осознанного процесса преодоления трудностей социокультурной адаптации.

Таким образом, актуальность темы исследования обусловлена необходимостью:

- представления целостной картины механизмов преодоления трудных жизненных ситуаций (социокультурной адаптации), что позволит обеспечить реализацию дальнейших научных исследований;

- $\quad$ разработки концептуальных положений, объясняющих роль осознанной саморегуляции и совладающего поведения в адаптации к новым социокультурным условиям;

- выработки теоретических положений о детерминационной роли социокультурных факторов в саморегуляции и совладании с трудными жизненными ситуациями.

Maтериалы и методы / Materials and methods. Анализ представленной проблемы включал несколько этапов. На первом этапе на основе анализа теоретических воззрений на проблему трудных жизненных ситуаций раскрывается потенциал когнитивных механизмов в совладании с трудными жизненными ситуациями. На втором этапе на основе системного анализа и синтеза теоретических положений раскрывается роль осознанной саморегуляции, совладающего поведения (копинг-стратегий) в ситуации социокультурной адаптации, переживания иностранными обучающимися аккультурационного стресса. Третий этап исследования раскрывает положения о детерминационной роли социокультурных факторов в саморегуляции и совладании с трудными жизненными ситуациями.

Теоретические выводы подтверждаются результатами эмпирических исследований. В эмпирическую выборку исследования входили 316 студентов. Выборка распределялась по этнокультурному признаку: студенты - представители европейской культуры ( 88 человек), студенты из арабских стран (Ирак, Марокко, Тунис, Палестина) - 22 человека; студентов из африканских стран (Ангола, ЮАР, Зимбабве, Нигерия) - 67 человек, студенты из среднеазиатских стран (Таджикистан, Узбекистан) - 111 человек, студенты из республик СКФО - 28 человек.

В исследования был использован комплекс методов, в том числе: опросник «Стиль саморегуляции поведения - ССПМ [9]», позволяющий диагностировать степень развития осознанной саморегуляции и ее индивидуальные профили, компонентами которых являются частные регуляторные процессы; методика исследования адаптированности студентов в вузе (Т. Д. Дубовицкая [4]), использовавшаяся для оценки резервных возможностей обучающихся и их готовности к преодолению разного рода трудностей, возникающих в процессе обучения (в психологической адаптации студентов принято выделять адаптацию к условиям учебной деятельности и адаптацию к группе); опросники аккультурационного стресса (An Acculturative Stress Scale for International Students, ASSIS) и «Шкала социокультурной адаптации» (Sociocultural Adaptation Scale, SCAS-R), включающая пять 10-балльных шкал оценки особенностей обучения в СКФУ; методика определения индивидуальных копинг-стратегий - опросник SACS - «Стратегии преодоления стрессовых ситуаций〉 (С. Хобфолл, 1994 [16]), согласно которой С. Хобфоллом предложена многоосевая модель преодоления, которая имеет оси: просоциальную / асоциальную, активную / пассивную, прямую / непрямую, -представляющие собой измерения общих стратегий преодоления; для исследования личностных особенностей студентов - опросник NEO-PI-R (Big Five Model of Personality (Costa \& McCrae, 1992, в адаптации А. Б. Хромова, 2000 [12]). 
Pезультаты и обсуждение / Results and discussion. На протяжении своей жизни каждый человек сталкивается с ситуациями, которые нарушают привычный уклад его жизни. Подобные ситуации в научной и научно-популярной литературе называют по-разному: стрессовые ситуации, жизненные трудности, травматические события, жизненные кризисы, критические ситуации. Трудные жизненные ситуации - это широкий спектр ситуаций и событий, нарушающих баланс, сложившийся между личностью и средой, фрустрирующих потребности человека и вызывающие у него психологический стресс, нарушения как невротического, так и соматического характера. Такие ситуации и события предъявляют повышенные требования к адаптационным механизмам индивида и его ресурсам (R. Lasarus, S. Folkman [17]).

Определение трудности ситуации задается самим человеком и зависит от восприятия, оценки, интерпретации, субъективной значимости данной ситуации. Не сама ситуация является травматической, а тот негативный смысл, который приобретает эта ситуация для человека. Вероятность успешного преодоления трудной жизненной ситуации зависит от того, как человек оценивает ситуацию, осмысливает пути выхода из нее, видит в ней себя.

По мнению В. Франкла, в жизни нет ни одной ситуации, которая бы не могла быть осмыслена и продуктивно использована, в том числе и критическая [14]. Новые смыслы могут стать определяющими в переживании критических ситуаций.

Важным интернальным фактором в индивидуально-личностной подсистеме переживания критических ситуаций, в значительной степени способствующим успешности ее решения, является саморегуляторная система (П. К. Анохина, Н. А. Бернштейна, В. А. Иванникова, Дж. Келли, Д. А. Леонтьев, Д. Н. Узнадзе, И. М. Фейгенберга, У. Эшби и др.)

Саморегуляторные механизмы являются базовыми для развития резилиантности - интегративной характеристики личности, обеспечивающей успешную адаптацию и готовность приспосабливаться под перемены различного характера.

Особое значение придается универсальности ресурсов саморегуляции. Эти ресурсы переструктурируют системные связи взаимодействия с миром и способны превращать в достоинства даже то, что на первый взгляд выглядит очевидным минусом [7].

Общепризнанной в мировой науке теорией саморегуляции на сегодняшний день является теория Чарльза Карвера и Майкла Шейера [13]. Опираясь на когнитивную парадигму психологии, ученые под саморегуляцией понимают когнитивные процессы, направленные не столько на познание, сколько на поведение, на достижение цели. Цель, с авторской позиции, выступает исходной точкой саморегуляции.

Отечественные ученые (Б. В. Зейгарник, А. Б. Холмогорова, Е. Мазур) рассматривают саморегуляцию как сознательный процесс, который направлен на управление своим поведением. Б. В. Зейгарник выделяет два уровня саморегуляции: операционально-технический и мотивационный [5]. Первая форма регуляции оптимальна в стандартных ситуациях, связанных с сознательной организацией действия с подключением средств оптимизации. Вторая форма саморегуляции (мотивационная) эффективна в критических ситуациях, когда достижение целей в силу объективных причин становится невозможным. Мотивационно уровень саморегуляции - это процесс, опосредованный социальными нормами и ценностями, системой внутренних требований человека. Культура создает особые формы поведения, она видоизменяет деятельность психических функций, она надстраивает новые этажи в развивающейся системе поведения человека [3].

В контексте понимания саморегуляции как целенаправленной активности (О. А. Конопкин [6], В. И. Моросанова [10], А.К. Осницкий [11]), саморегуляция рассматривается как процесс инициации и выдвижения субъектом целей активности, а также управление достижением этих целей. Предметом психологии саморегуляции являются интегративные психические явления и процессы, обеспечивающие самоорганизацию различных видов психической активности человека, целостность его индивидуальности [8]. На операциональном уровне саморегуляция - 
это субсистема когнитивных процессов планирования целей, моделирование значимых условий их достижения, программирование последовательности и способов действий, оценивание и корректирование их результатов. На личностном уровне саморегуляция представлена своеобразием инструментальных личностно-регуляторных свойств, таких как гибкость, надежность ответственность, инициативность, рефлексивность [10]. Отвечая современным тенденциям интегративных психологических концепций, развитие осознанной саморегуляция зависит как от ее когнитивного уровня, так и от личностного. Лежащие в основе саморегуляции осознанные смысловые образования, осуществляют изменения, оценку и коррекцию деятельности, поведения, формируя новые ценности, которые лежат в основе целостной жизнедеятельности человека. Осознанная саморегуляция рассматривается как метаресурс, позволяющий субъекту деятельности осознанно и самостоятельно выдвигать цели и управлять их достижением при помощи универсальных и специальных регуляторных компетенций [10].

Трудности, которые возникают в процессе активной социализации и аккультурации, оказываются связанными не только со сложностью структуры окружения и неоднозначностью его семантики, но и с малой степенью осознания людьми адекватности собственного поведения и возможности контроля над ним. В связи с этим актуальной становится роль осознанной саморегуляции как целенаправленного процесса управления всеми видами внешней и внутренними активности, ресурсами, направленными на построение модели окружающего мира и оптимальной адаптации к ней. Наши исследования показали взаимосвязи компонентов осознанной саморегуляции с общим уровнем аккультурационного стресса.

Данные, представленные в таблице, позволяют сделать вывод: сформированность стилевой характеристики - программирование (Пр), особенностей регуляторно-личностных свойств (гибкость (Г), самостоятельность (С)) снижают вероятность деструктивного характера переживания аккультурационного стресса $(\mathrm{r}=-0,41)$ (таблица 1$)$.

\section{Взаимосвязь показателей осознанной саморегуляции}

Таблища 1

с общим уровнем аккультурационного стресса

\begin{tabular}{|c|c|c|c|c|c|c|c|}
\hline & Пл & М & Пр & ОР & Г & С & ОУрС \\
\hline Общий уровень аккультурационного стресса & $-0,27$ & $-0,12$ & $-0,32$ & $-0,07$ & $-0,47$ & $-0,31$ & $-0,41$ \\
\hline
\end{tabular}

Саморегуляцию традиционно описывают в терминах адаптации, защиты и совладания. В последнее годы связь совладания с саморегуляцией подтверждается научными исследованиями как отечественных (И. И. Ветрова, Е. А. Сергиенко, Т. Л. Крюкова), так и зарубежных (E. A. Skinner, J. R. Pitzer, J. S. Steele) ученых. Само определение совладания - это «регуляция действий в условиях стресса), процессы, направленные на оптимальное решение разного рода проблем, адаптацию человека к требованиям ситуации, восстановление психологического благополучия.

Исследования копинг-стратегий имеют свою историю. Первоначально они изучались в рамках психодинамического подхода как психологическая защита, далее, как реакция человека на стрессовые ситуации [18]. В последнее время исследования копинг-стратегий развертываются в рамках изучения реагирования субъекта на трудности и неудачи в выполнении учебной, профессиональной деятельности, в мотивации достижения, саморегуляции, целеполагания. Д. А. Леонтьев рассматривает копинг-стратегии как компоненты личностного потенциала, определяющего успешность саморегуляции в различных ситуациях деятельности [7].

Выделяют три линии исследований совладания с трудными жизненными ситуациями. Согласно первой, исследуют особенности совладающего поведения с одним типом ситуаций; вторая группа исследований погружает в проблему особенностей совладания с разными типами ситуаций; третья линия исследований совладания проходит в контексте комплексного подхода. 
Исследования особенностей копинг-стратегий в рамках одного типа ситуаций акцентируют внимание на анализе отдельных типовых ситуаций, например: экзамена (Т. Л. Крюкова, N. Bolger), учебных ситуаций (Е. C. Chang), рабочих ситуаций (В. C. Long), ситуаций с заболеваниями (J. R. Weisz et al.). Изучается влияние личностных, возрастных, гендерных особенностей на выбор копинг-стратегий.

Гибкость / устойчивость совладающего поведения в разных ситуациях, когнитивная оценка событий, влияние ситуационных факторов на выбор стратегии в нескольких типах ситуаций это второе направление исследования совладающего поведения в трудных жизненных ситуациях (E. B. Band, J. R. Weisz; E. Wethington, R. Kessler).

Комплексный подход подразумевает учет одновременно разных групп факторов-детерминант совладания (личностные диспозиции, когнитивное оценивание ситуации, учет ситуационных факторов). Р. Лазарус и С. Фолкман [18] описывают копинг как результат взаимодействия личности и ситуации - личность проводит субъективную оценку ситуации. Если ситуация меняется, меняется ее когнитивное оценивание, что влечет изменения совладающего поведения. Личностные диспозиции также могут влиять на выбор копинг-поведения посредством оценок, включающих оценку угрозы ситуации для жизни, возможности контролировать ситуацию, возможность получения социальной помощи (J. Hudek-Knezevic, I. Kardum). Выявлены взаимосвязи копинг-стратегий с характеристиками интеллектуального потенциала субъекта (Т. В. Корнилова), особенностями саморегуляции (Т. Н. Банщикова, Е. А. Фомина, В. А. Соломонов) (таблица 2).

Таблича 2

Взаимосвязь копинг-стратегий с показателями осознанной саморегуляции и показателями аккультурационного стресса

\begin{tabular}{|c|c|c|c|c|c|c|c|c|c|}
\hline & 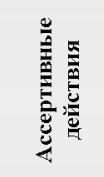 & 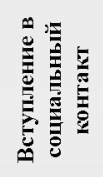 & 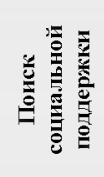 & 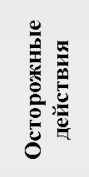 & 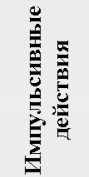 & 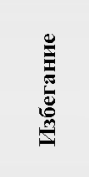 & 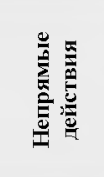 & 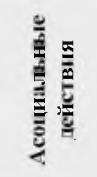 & 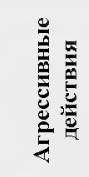 \\
\hline \multicolumn{10}{|c|}{ Компоненты осознанной саморегуляции } \\
\hline планирование & 0,38 & 0,42 & 0,40 & 0,37 & 0,14 & 0,09 & 0,16 & $-0,05$ & $-0,01$ \\
\hline моделирование & $-0,01$ & 0,08 & 0,11 & $-0,02$ & $-0,09$ & 0,00 & 0,00 & $-0,10$ & $-0,09$ \\
\hline программирование & 0,26 & 0,33 & 0,38 & 0,28 & 0,08 & $-0,02$ & 0,02 & $-0,19$ & $-0,12$ \\
\hline оценивание результатов & $-0,06$ & 0,01 & 0,06 & $-0,01$ & 0,05 & $-0,13$ & $-0,06$ & $-0,20$ & $-0,16$ \\
\hline гибкость & 0,47 & 0,52 & 0,50 & 0,32 & 0,17 & 0,06 & 0,14 & $-0,02$ & $-0,04$ \\
\hline самостоятельность & 0,16 & $-0,09$ & $-0,02$ & $-0,01$ & $-0,01$ & $-0,15$ & 0,03 & $-0,01$ & 0,00 \\
\hline OУpC & 0,45 & 0,47 & 0,54 & 0,38 & 0,18 & 0,00 & 0,14 & $-0,15$ & $-0,12$ \\
\hline \multicolumn{10}{|c|}{ Показатели аккультурационного стресса } \\
\hline $\begin{array}{l}\text { Общий уровень аккультур. } \\
\text { стресса }\end{array}$ & $-0,03$ & $-0,19$ & $-0,19$ & $-0,04$ & 0,13 & 0,08 & 0,03 & 0,22 & 0,14 \\
\hline $\begin{array}{l}\text { Воспринимаемая дискрими- } \\
\text { нация }\end{array}$ & 0,10 & $-0,01$ & $-0,03$ & 0,13 & 0,24 & 0,19 & 0,11 & 0,28 & 0,22 \\
\hline Тоска по дому & 0.09 & 0,18 & 0,20 & 0,11 & 0,02 & 0.13 & 0,18 & 0,12 & 0.17 \\
\hline $\begin{array}{l}\text { Воспринимаемая } \\
\text { враждеб̆ость }\end{array}$ & $-0,01$ & $-0,25$ & $-0,25$ & $-0,16$ & 0,15 & 0,02 & $-0,09$ & 0,19 & 0,02 \\
\hline Страх & $-0,26$ & $-0,27$ & $-0,25$ & $-0,06$ & 0,08 & 0,10 & $-0,05$ & 0,22 & 0,13 \\
\hline Культурный шок & $-0,01$ & $-0,25$ & $-0,19$ & $-0,01$ & 0,10 & 0,06 & 0,06 & 0,14 & 0,14 \\
\hline
\end{tabular}


В нашем исследовании установлены положительные корреляционные связи активных (ассертивные действия), просоциальных (вступление в социальный контакт, поиск социальной поддержки) и пассивных (осторожные действия) копинг-стратегий с показателями осознанной саморегуляции (планирование, программирование, гибкость общий уровень саморегуляции), а также отрицательные связи показателей переживания аккультурационного стресса (страх, культурный шок, воспринимаемая враждебность) с просоциальными копинг-стратегиями. Не установлена взаимосвязь показателей осознанной саморегуляции и аккультурационного шока с прямыми / непрямыми и асоциальными копинг-стратегиями.

В опоре на методологические традиции отечественной психологии (в частности, концепцию В. И. Моросановой и ее последователей) обоснована модель, рассматривающая осознанную саморегуляцию как метаресурс, позволяющий субъекту деятельности осознанно и самостоятельно выбирать копинг-стратегии, определяющие успешность адаптации к новой социокультурной среде.

Как было отмечено выше, саморегуляция - это процесс, опосредованный социальными нормами и ценностями, системой внутренних требований человека. Культура видоизменяет деятельность психических функций, надстраивая новые этажи в развивающейся системе поведения человека [3].

В кросс-культурных исследованиях раскрываются особенности поведения людей, их психики с точки зрения детерминации социокультурными факторами. С позиции кросс-культурного подхода особенности осознанной саморегуляции и совладающего поведения рассматриваются как культуроспецифические, единые, универсальные для представителей одной культуры. В центре внимания кросс-культурного подхода к описанию различий в поведенческих и психологических признаках должна оказаться не столько социокультурная среда, сколько причинно-следственные связи между поведенческими признаками, которые характерны для носителей той или иной культуры и социокультурным контекстом развития представителей данной культуры. Социокультурный контекст выступает источником рассмотрения различий по широкому спектру психологических признаков от когнитивных процессов до личностных черт (Д. Берри, А. Пуртинга, М. Сигалл, П. Дасен).

Рассматривая саморегуляцию, совладеющее поведение как сознательный процесс, направленный на управление своей произвольной активностью, как ценностную позицию, которая формируется в процессе социализации - инкультурации, происходящей в конкретном регионе, в конкретное время, в конкретных обстоятельствах, то вполне обоснованной является необходимость установления особенностей конкретного социокультурного пространства, в котором общие характеристики саморегуляции всегда приобретают особый характер (Т. Н. Банщикова, В. И. Моросанова [1]).

Наши исследования установили значимые различия / сходства в показателях саморегуляции, совладающего поведения у представителей разных культур (таблица 3 ).

Таблича 3

Сравнение средних значений показателей осознанной саморегуляции и стратегий преодолеваюшего поведения

\begin{tabular}{|c|c|c|c|c|c|}
\hline Шкалы саморегуляции & Студенты РФ & $\begin{array}{c}\text { Студенты } \\
\text { дальнего } \\
\text { зарубежья }\end{array}$ & $\begin{array}{l}\text { Студенты } \\
\text { ближнего } \\
\text { зарубежья }\end{array}$ & ANOVA & $\begin{array}{c}\text { Критерий } \\
\text { Краскела - } \\
\text { Уоллиса }\end{array}$ \\
\hline \multicolumn{6}{|c|}{ Комопненты осознанной саморегулящии } \\
\hline Планирование & 6,0 & 6,0 & 6,4 & 0,2235 & \\
\hline Моделирование & 5,7 & 4,7 & 5,4 & 0,0060 & 0,0060 \\
\hline Программирование & 5,9 & 5,7 & 5,9 & 0,6457 & \\
\hline Оценивание результатов & 6,1 & 5,2 & 5,1 & 0,0005 & 0,0005 \\
\hline Гибкость & 6,8 & 5,7 & 6,3 & 0,0012 & 0,0012 \\
\hline
\end{tabular}




\begin{tabular}{|c|c|c|c|c|c|}
\hline Шкалы саморегуляции & Студенты РФ & $\begin{array}{c}\text { Студенты } \\
\text { дальнего } \\
\text { зарубежья }\end{array}$ & $\begin{array}{c}\text { Студенты } \\
\text { ближнего } \\
\text { зарубеежья }\end{array}$ & ANOVA & $\begin{array}{c}\text { Критерий } \\
\text { Краскела - } \\
\text { Уоллиса }\end{array}$ \\
\hline Самостоятельность & 5,0 & 5,3 & 5,0 & 0,6134 & \\
\hline OypC & 30,1 & 28,1 & 29,2 & 0,0682 & \\
\hline \multicolumn{6}{|c|}{ Копинг-стратегии } \\
\hline Ассертивные действия & 19,9 & 21,0 & 20,4 & 0,1810 & \\
\hline Вступление в социальный контакт & 22,0 & 22,1 & 22,0 & 0,9828 & \\
\hline Поиск социальной поддержки & 22,4 & 22,4 & 22,2 & 0,9445 & \\
\hline Осторожные действия & 20,0 & 20,9 & 20,3 & 0,4641 & \\
\hline Импульсивные действия & 18,5 & 18,4 & 18,8 & 0,6456 & \\
\hline Избегание & 17,5 & 18,7 & 17,2 & 0,0329 & 0,0414 \\
\hline Непрямые действия & 18,8 & 18,8 & 18,4 & 0,7857 & \\
\hline Асоциальные действия & 16,9 & 16,6 & 17,2 & 0,6840 & \\
\hline Агрессивные действия & 18,9 & 17,2 & 17,1 & 0,0368 & 0,0398 \\
\hline
\end{tabular}

На основании анализа взаимосвязей компонентов осознанной саморегуляции, копинг-стилей и показателей аккультурационного стресса можно сделать следующие выводы.

Студенты из республик СКФО более успешны в определении значимых условий достижения целей как в текущей ситуации, так и в перспективном будущем, у них более устойчивые субъективные критерии оценки результатов своих действий и поступков, они способны быстрее, чем их зарубежные одногруппники, оценить изменения значимых условий и перестраивать программу своих действий.

Студенты из дальнего зарубежья отличаются от других респондентов тем, что имеют относительно слабую сформированность процессов моделирования. Это приводит к неадекватной оценке внутренних условий и внешних обстоятельств, что может сопровождаться резкими перепадами отношения к развитию ситуации, последствиям своих действий. У таких студентов могут возникать трудности в определении цели и программы действий, адекватных текущей ситуации, где они не всегда замечают изменение ситуации и не могут подстроиться под неё. В динамичной атмосфере вуза иностранцы часто чувствуют себя неуверенно, что свидетельствует о том, что они с трудом привыкают к переменам в жизни, к смене обстановки и образа жизни. В результате у иностранных студентов из дальнего зарубежья возникают регуляторные сбои и, как следствие, неудачи в выполнении учебных задач.

По результатам методики выявления предпочитаемых стратегий преодоления затруднительных ситуаций Хобфолла, были выявлены статистически значимые различия среди исследуемых групп респондентов по показателям «избегание» $(p=0,0414)$ и «агрессивные действия» $(p=0,0398)$.

У российских студентов наиболее выражена асоциальная стратегия преодоления - «Агрессивные действия», у студентов из ближнего зарубежья асоциальные прямые действия - «Импульсивные действия», «Асоциальные действия», тогда как студенты из дальнего зарубежья более активно чем другие студенты используют просоциальные активные и пассивные стратегии («Ассертивные действия», «Вступление в социальный контакт», «Поиск социальной поддержкки), «Осторожные действия), (Импульсивные действия», «Избегание»).

Таким образом, существует определенная специфика регуляторно-личностных особенностей иностранных и российских студентов. Иностранные студенты, преимущественно из дальнего зарубежья, демонстрируют несформированность потребности в осознанном планировании и программировании своего поведения. 
Российские студенты отличаются высоким уровнем саморегуляции, регуляторно-личностными характеристиками - самостоятельность, гибкость - и адекватно реагируют на изменение условий. Выдвижение и достижение цели у них в значительной степени осознанно. При высокой мотивации достижения они способны проявлять такой стиль саморегуляции, который позволяет компенсировать влияние личностных, характерологических особенностей, препятствующих достижению цели. Опираясь на методологические традиции отечественной психологии саморегуляции обоснованным выступает предположение: чем выше общий уровень осознанной регуляции, тем легче человек овладевает новыми видами активности, увереннее чувствует себя в незнакомых ситуациях, а его успехи в привычных видах деятельности приобретают характер стабильности.

Заключение /Conclusion. Проведенный анализ теоретических воззрений на проблему трудных жизненных ситуаций позволил раскрыть потенциал когнитивных механизмов в совладании с трудными жизненными ситуациями, раскрыть роль осознанной саморегуляции, совладающего поведения в преодолении трудностей социокультурной адаптации, переживании аккультурационного стресса иностранными обучающимися. Кросс-культурный анализ показателей саморегуляции и совладающего поведения позволил раскрыть универсальные, культуроспецифические, единые для представителей одной культуры особенности.

Осознанная саморегуляция студентов, переживающих аккультурационный стресс, имеет выраженную этнокультурную специфику по составу предикторов регуляторики. Аккультурационный стресс у студентов - представителей исламских культур затрагивает не только отдельные регуляторные процессы и личностно-регуляторные свойства, но и интегральный уровень саморегуляции.

\section{ЛИТЕРАТУРА И ИНТЕРНЕТ-РЕСУРСЫ}

1. Банщикова Т. Н. Региональная специфика индивидуально-типологических особенностей взаимосвязи саморегуляции и агрессии у педагогов / Т. Н. Банщикова, В. И. Моросанова // Вестник Северо-Кавказского федерального университета. - 2016. - № 1 (52). - С. 114-121.

2. Берри Джон В. Кросс-культурная психология. Исследования и применение / В. Берри Джон, Х. Пуртинга Айп, Х. Сигалл Маршалл. - Харьков : Гуманитарный центр, 2007. -560 с.

3. Выготский, Л. С. История развития высших психических функций / Л. С. Выготский // Собрание сочинений. - Москва : Педагогика, 1983. - Т. 3. - С. 6-328.

4. Дубовицкая Т. Д. Методика исследования адаптированности студентов в вузе / Т. Д. Дубовицкая, А. В. Крылова // Психологическая наука и образование. - 2010. - № 2. - С. 1-12.

5. Зейгарник Б. В. Саморегуляция поведения в норме и патологии / Б. В. Зейгарник, А. Б. Холмогорова, Е. Мазур // Психологический журнал. - 1989. - Т. 2. - № 2. - С. 122-132.

6. Конопкин О. А. Психологические механизмы регуляции деятельности / О. А. Конопкин. - Москва : ЛЕНАНД, 2018. - $320 \mathrm{c}$.

7. Леонтьев Д. А. Саморегуляция, ресурсы и личностный потенциал / Д. А. Леонтьев // Сибирский психологический журнал. - 2016. - № 62. - С. 18-37.

8. Моросанова В. И. Самосознание и саморегуляция поведения / В. И. Моросанова, Е. А. Аронова. Москва : Институт психологии РАН, 2007. - 213 с.

9. Моросанова В. И. Опросник «Стиль саморегуляции поведения» (ССПМ) : руководство / В. И. Моросанова. - Москва : Когито-Центр, 2004. - 44 с.

10. Моросанова В. И. Осознанная саморегуляция как метасистема психологических ресурсов достижения целей и саморазвития человека / В. И. Моросанова // Фундаментальные и прикладные исследования современной психологии: результаты и перспективы развития / отв. ред. А. Л. Журавлев, В. А. Кольцова. - Москва : Институт психологии РАН, 2017. - С. 501-509.

11. Осницкий А. К. Дифференциальные аспекты регуляции активности человека / А. К. Осницкий // Психология XXI века: теория, практика, перспективы. - 2013. - С. 34-45. 
12. Хромов А. Б. Пятифакторный опросник личности : учебно-методическое пособие / А. Б. Хромов. Курган : Изд-во Курганского гос. университета, 2000. -23 с.

13. Carver C. Perspectives on Personality / C. Carver, M. Scheier. -4 ed. -Boston etc. : Allyn \& Bacon, 2000.

14. Frankl V. Man's Search for Meaning: Collection / V. Frankl; trans. from English and therein total. cd. L. Y. Gozman and D. A. Leontyev, vst. st. D. A .Leontyev. - Moscow : Progress Publishers, 1990 - 368 p.

15. Higgins T. Self-regulation and quality of life: Emotional and non-emotic life experiences / T. Higgins, H. Grant, J. Shah // Well-being: The foundations of hedonic psychology / D. Kahner, E. Diener, N. Schwarz (Eds.). - New York : Russell Sage Foundation, 1999. - P. 244-266.

16. Hobfoll S. E. et al. Gender and coping: The dual-axis model of coping / S. E. Hobfoll et al. // American Journal of Community Psychology. 1994. Vol. 22, № 1. P. 49-82.

17. Lazarus R. S. Stress, appraisal and coping / R. S. Lazarus, S. Folkman. - New York, 1984.

18. Long B. C. Relation between coping strategies, sex-typed traits, and environmental characteristics : a comparison of male and female managers / B. C. Long // J. of Counseling Psychol. 1990. Vol. 37. N 2. P. 185-194.

19. Tumanova E. N. Help the adolescent life in a crisis situation / E. N. Tumanova - Saratov : Slovo, 2002. -69 p.

\section{REFERENCES AND INTERNET RESOURCES}

1. Banshchikova T. N. Regional'naya spetsifika individual'no-tipologicheskikh osobennostei vzaimosvyazi samoregulyatsii i agressii u pedagogov / T. N. Banshchikova, V. I. Morosanova // Vestnik SeveroKavkazskogo federal'nogo universiteta. - 2016. - No 1 (52). - S. 114-121.

2. Berri Dzhon V. Kross-kul'turnaya psikhologiya. Issledovaniya i primenenie / V. Berri Dzhon, Aip X. Purtinga, Marshall X. Sigall. - Khar'kov: Gumanitarnyi tsentr, 2007. $560 \mathrm{~s}$.

3. Vygotskii L. S. Istoriya razvitiya vysshikh psikhicheskikh funktsii / L. S. Vygotskii // Sobranie sochinenii. Moskva : Pedagogika, 1983. T. 3. S. 6-28.

4. Dubovitskaya T. D. Metodika issledovaniya adaptirovannosti studentov v vuze / T. D. Dubovitskaya, A. V. Krylova // Psikhologicheskaya nauka i obrazovanic. - 2010. - No 2. - S. 1-12.

5. Zeigarnik B. V. Samoregulyatsiya povedeniya v norme i patologii / B. V. Zeigarnik, A. B. Kholmogorova, E. Mazur // Psikhologicheskii zhurnal. - 1989. - T. 2. - No 2. - S. 122-132.

6. Konopkin O. A. Psikhologicheskie mekhanizmy regulyatsii deyatel'nosti / O. A. Konopkin. - Moskva : LENAND, 2018. $-320 \mathrm{~s}$.

7. Leont'ev D. A. Samoregulyatsiya, resursy i lichnostnyi potentsial / D. A. Leont'ev // Sibirskii psikhologicheskii zhurnal. - 2016. - No 62. - S. 18-37.

8. Morosanova V. I. Samosoznanie i samoregulyatsiya povedeniya / V. I. Morosanova, E. A. Aronova. Moskva : Institut psikhologii RAN, 2007. - 213 s.

9. Morosanova V. I. Oprosnik «Stil’ samoregulyatsii povedeniya» (SSPM): rukovodstvo / V. I. Morosanova. Moskva : Kogito-Tsentr, 2004. - 44 s.

10. Morosanova V. I. Osoznannaya samoregulyatsiya kak metasistema psikhologicheskikh resursov dostizheniya tselei i samorazvitiya cheloveka / V. I. Morosanova // Fundamental'nye i prikladnye issledovaniya sovremennoi psikhologii: rezul'taty i perspektivy razvitiya / otv. red. A. L. Zhuravlev, V. A. Kol'tsova. - Moskva : Institut psikhologii RAN, 2017. - S. 501-509.

11. Osnitskii A. K. (Differentsial'nye aspekty regulyatsii aktivnosti cheloveka) / A. K. Osnitskii // Psikhologiya XXI veka: teoriya, praktika, perspektivy. -2013 . - S. 34-45.

12. Khromov A. B. Pyatifaktornyi oprosnik lichnosti: uchebno-metodicheskoe posobie / A. B. Khromov. Kurgan : Izd-vo Kurganskogo gos. universiteta, 2000. $-23 \mathrm{~s}$.

13. Carver C. Perspectives on Personality / C. Carver, M. Scheier. -4 ed. - Boston etc. : Allyn \& Bacon, 2000.

14. Frank1 V. Man's Search for Meaning : Collection / V. Frankl; trans. from English and therein total. cd. L. Y.Gozman and D. A. Leontyev, vst. st. D. A .Leontyev. - Moscow : Progress Publishers, 1990. - 368 p.

15. Higgins T. Self-regulation and quality of life: Emotional and non-emotic life experiences / T. Higgins, H. Grant, J. Shah // Well-being: The foundations of hedonic psychology / D. Kahner, E. Diener, N. Schwarz (Eds.). - New York : Russell Sage Foundation, 1999. - P. 244-266. 
16. Hobfoll S. E. et al. Gender and coping: The dual-axis model of coping / S. E. Hobfoll et al. // American Journal of Community Psychology. 1994. Vol. 22, № 1. P. 49-82.

17. Lazarus R. S. Stress, appraisal and coping / R. S. Lazarus, S. Folkman. - New York, 1984.

18. Long B. C. Relation between coping strategies, sex-typed traits, and environmental characteristics : a comparison of male and female managers / B. C. Long // J. of Counseling Psychol. 1990. Vol. 37. N 2. P. $185-194$.

19. Tumanova E. N. Help the adolescent life in a crisis situation / E. N. Tumanova. - Saratov : Slovo, 2002. -69 p.

\section{СВЕДЕНИЯ ОБ АВТОРАХ}

Банцикова Татьяна Николаевна, кандидат психологических наук, доцент, Северо-Кавказский федеральный университет. E-mail: sevkav@mail.ru

Ширяева Ирина Сергеевна, преподаватель, Сергиево-Посадский аграрный колледж (г. Сергиев-Посад). E-mail: iriha91@mail.ru

\section{INFORMATION ABOUT AUTHORS}

Tatyana Banshchikova, candidate of psychological sciences, associate professor, North Caucasian Federal University. E-mail: sevkav@mail.ru

Irina Shiryaeva, teacher, Sergiev Posad Agricultural College (Sergiev Posad). E-mail: iriha91@mail.ru 